\title{
Araştırma Makalesi / Research Article Bir Boyutlu Analiz Yöntemiyle Sahaya Özel Sıvılaşma Risk Haritalarının Oluşturulması: Afyonkarahisar Örneği
}

\author{
Süleyman GÜCEK ${ }^{1}$, İsmail ZORLUER ${ }^{2}$ \\ ${ }^{1,2}$ Afyon Kocatepe Üniversitesi, Mühendislik Fakültesi, Inşaat Mühendisliği Bölümü, 03200, Afyonkarahisar.
}

Sorumlu yazar, e-posta: sgucek@aku.edu.trＯRCIDID: https://orcid.org/0000-0002-4839-1851

izorluer@aku.edu.tr ORCIDID: https://orcid.org/0000-0001-5017-084X

Geliş Tarihi: 01.05.2021 Kabul Tarihi: 13.08.2021

\section{Anahtar kelimeler Sıvılaşma Riski; Doğrusal Olmayan Analiz; Coğrafi Bilgi Sistemleri; Mikrobölgeleme}

Öz

Can ve mal kayıplarıyla birlikte ciddi anlamda maddi ve manevi kayıplara neden olan depremlerin, meydana gelen doğal afetlerin önlenmesi ne yazık ki mümkün değildir. Lakin depremlerin meydana getirebileceği hasarı minimum seviyeye indirgemek mümkündür. Deprem esnasında meydana gelen sismik dalgaların meydana getirdiği tekrarlı kayma gerilmeleri altında, boşluk suyu basıncındaki ani artışa bağlı olarak suya doygun siltli, kumlu ve kil oranı az olan zeminlerde, efektif gerilmenin azalması sonucunda zeminin mukavemet kaybına bağlı olarak sıvı gibi davranması neticesinde yapısal hasarlar meydana getirmektedir. Türkiye tektoniğinde çok önemli bir konumda bulunan Afyonkarahisar ili ve çevresinde birçok aktif fay bulunmaktadır. Bu sebeple sıvılaşmaya bağlı olumsuz etkilerinin azaltılabilmesi için, dinamik (tekrarı) yüklerin etkisi altındaki yerel zeminlerin nasıl bir davranış göstereceğinin araştırılması, sıvılaşma potansiyelinin önceden belirlenmesi büyük önem arz etmektedir. Bu çalışma kapsamında yerel zemin koşullarının sıvılaşmaya etkisini incelemek amacıyla, Anakaya mostrasındaki yer hareketi olarak Türkiye Bina Deprem Yönetmeliği'ne(2018) uygun olarak seçilmiş olan 11 farklı deprem kaydı verisi kullanılarak bir boyutlu (1-B) dinamik analizler yapılmıştır. Bu kapsamda bölgede yapılmış olan 124 farklı sondaj kuyusu verisi değerlendirilerek çalışma bölgesinin yerel zemin özellikleri belirlenmiştir. Arazi ve laboratuvar verileri kullanılarak zemin özelliklerinin dinamik davranışa etkisini incelemek amacıyla DeepSoil v6.1 yazııımı kullanıımıştır. Bir boyutlu doğrusal olmayan analiz yöntemi kullanılarak her sondaj için sıvılaşma analizleri yapılmıştır. TBDY (2018)'e göre sıvılaşma riski olan zeminlerde, zaman tanım alanında bir boyutlu doğrusal olmayan analiz yöntemi tercih edilmiştir. Bu çalışma neticesinde analiz sonuçları ile birlikte elde edilen veriler değerlendirilerek, çalışma bölgesi sıvılaşma risk haritalarının oluşturulması, bölgedeki bulunan mevcut yapılar ile inşa edilmesi planlanan binaların temel zeminlerinin dinamik davranışlarının belirlenmesi hedeflenmiştir.

\section{Generating Site-Specific Liquefaction Risk Maps with One Dimensional Analysis Method: A Case Study In Afyonkarahisar}

\footnotetext{
Abstract

Unfortunately, it is not possible to prevent earthquakes and natural disasters that cause serious material and moral losses along with loss of life and property. However, it is possible to minimize the

Keywords

Liquefaction Risk;

Nonlinear Analysis;

Geographic

Information Systems;

Microzonation damage caused by earthquakes. Under the repeated shear stresses caused by the seismic waves that occur during the earthquake, due to the sudden increase in the pore water pressure, the soils with saturated silty, sandy and low clay content cause structural damage as a result of the soil acting like a liquid due to the loss of strength as a result of the decrease in the effective stress. There are many active faults in and around Afyonkarahisar province, which has a very important position in the tectonics of Turkey. For this reason, in order to reduce the negative effects of liquefaction, it is of great importance to investigate the behavior of local soils under the influence of dynamic (repetitive) loads and to determine the liquefaction potential beforehand. Within the scope of this study, onedimensional (1-D) dynamic analyzes were carried out using 11 different earthquake record data selected in accordance with the Turkish Building Earthquake Code (2018) as the ground motion in the
} 
bedrock outcrop in order to examine the effect of local soil conditions on liquefaction. In this context, the local soil characteristics of the study area were determined by evaluating the data of 124 different boreholes made in the region. DeepSoil v6.1 software was used to examine the effect of soil properties on dynamic behavior using field and laboratory data. Liquefaction analyzes were performed for each borehole using a one-dimensional nonlinear analysis method. According to TBDY (2018), a onedimensional nonlinear analysis method was preferred in the time history for soils with liquefaction risk. As a result of this study, it was aimed to evaluate the data obtained together with the results of the analysis, to create liquefaction risk maps of the study area, to determine the dynamic behavior of the existing structures in the region and the foundation soil of the buildings planned to be built.

(c) Afyon Kocatepe Üniversitesi

\section{Giriş}

Yeryüzünde en etkin deprem kuşaklarından birinin üzerinde yer alan Türkiye'de günümüze kadar meydana gelmiş olan depremler neticesinde birçok yapının hasar görmesi ya da yıkılmasındaki en önemli etkenlerin başında geoteknik ve jeolojik özellikler ile birlikte yapılaşma esnasındaki yanlışlıkların olduğu açıkça görülmektedir(Taşdelen vd. 2016). Bu sebeple depreme dayanıklı yapıların inşasında; bölgeyi etkileyebilecek deprem kaynaklarının özellikleri, zemin koşulları ve yapıların mühendislik özellikleri beraber değerlendirilmelidir (Saita vd. 2012). Deprem hareketi esnasında yapıların dinamik davranışlarını araştırmak, deprem anında zeminlerin nasıl davranış göstereceğini tahmin etmek ve depreme dayanıklı yapılar tasarlamak en önemli etkenler arasındadır. Bu sebeple deprem kaynak parametrelerinin daha önceden bilinmesi ve zeminin nasıl bir davranış göstereceğinin analizi önemli hale gelmektedir. Zemin-Deprem davranışının modellenmesi ve analiz sonuçlarına göre yapıların tasarlanması halinde can ve mal kayıplarının en aza indirilmesi sağlanabilir (Tunçel vd. 2019).

Dünyadaki birçok şehir taşıma gücü düşük olan zeminler üzerine inşa edilmiştir (Değerliyurt 2014). Dünyada ve ülkemizde, alüvyon zemin üzerine inşa edilen yapıların depremler esnasında ciddi hasar gördüğü veya yıkıldığı 1964 yılında Nigata (Japonya) ve Büyük Alaska (ABD), 1999 Kocaeli ve Düzce (Türkiye) depremlerinde açıkça görülmüştür (Toprak ve Jinguuji 2006, Yasuda vd. 2012, Yamaguchi vd. 2012, Bray vd. 2014, Toprak vd. 2016). Devlet Su İşleri (DSi) sondaj verilerine göre,

inceleme alanının 160 metre derinliğe kadar ulaşan alüvyon zemine sahip olduğu bilinmektedir.
Inceleme alanının, Afyonkarahisar il merkezi ve çevresinde oluşabilecek büyük bir depremden etkilenme olasıllğı yüksek olduğundan dinamik özelliklerinin belirlenmesi büyük önem arz etmektedir.

Inceleme alanı zemin dağılımının siltli, killi ve kumlu formasyonlardan oluşması, bölgede yer altı su seviyesinin yüksek olmasından kaynaklı, deprem esnasında meydana gelebilecek sıvılaşma riski, Afyonkarahisar için önemli bir tehlike olarak görülmektedir (Bayrakçı vd. 2013). Bu tehlikeler dikkate alınarak incelenen bölgede zemin koşullarına bağı olarak deprem dalgaları neticesinde oluşabilecek değişimlerin belirlenmesi için en basit yaklaşım, düşey yönde ilerleyen kayma dalgası hızı yayılımına bağı olan bir boyutlu dinamik analiz yöntemdir (Kramer 1996, Özkan 2017).

Bu çalışmanın temel amacı, inceleme alanında daha önce böyle bir çalışmanın olmaması ve bu sebeple ilk defa yapılan bir boyutlu doğrusal olmayan analiz yöntemi kullanılarak inceleme bölgesinin sıvılaşma riskini belirleyerek kamu yararına sunmak amacıyla coğrafi bilgi sistemleri(CBS) teknikleri ile konuma dayalı olarak haritalamaktır.

\section{Materyal ve Metot}

\subsection{Materyal}

İnceleme alanı 1/35.000 ölçekli K 25-b4 pafta, 3437000-3444000 kuzey enlemleri ile 48660004870000 doğu boylamları içerisinde bulunmaktadır. Inceleme bölgesine kuzeybatıdan giren, bölgenin merkezinden geçerek şehrin doğusundan çıkan Akarçay Nehri bulunmaktadır (Şekil 1). 


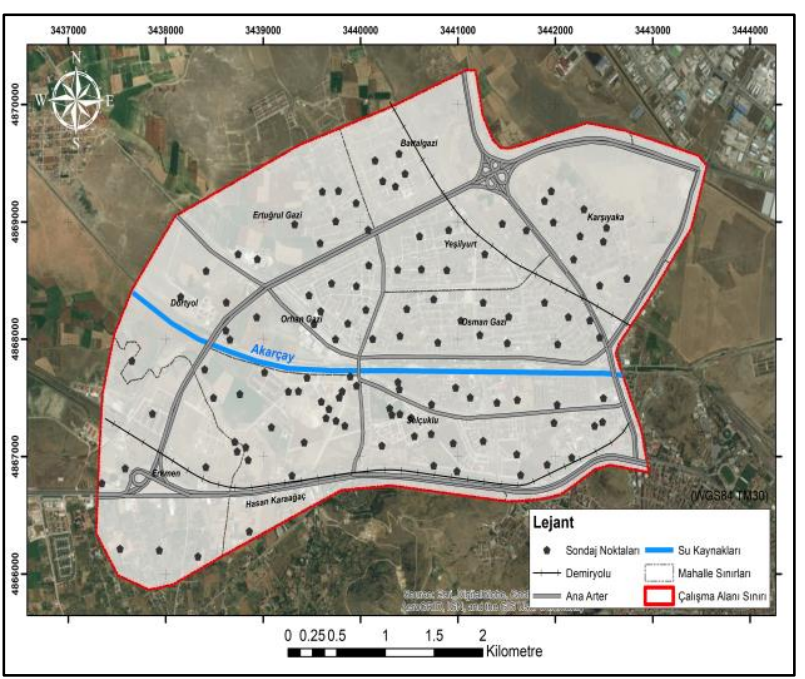

Şekil 1. İnceleme alanı ve sondaj noktalarının genel dağılımı

Inceleme alanında ovalar ve dere yatakları boyunca geniş bir alanı kapsayan alüvyon zemin formasyonu bulunmaktadır(Şekil 2). Çalışma alanının bulunduğu alan alüvyonal bir düzlük üzerinde yer almaktadır.

Bayramgazi şistleri ve Oyuklutepe Mermerlerinden oluşan Paleozoyik yaşı Afyon Metamorfikleri inceleme alanındaki temel kayaçlardır. Paleozoyik birimlerin üzerine uyumsuz olarak killi kireçtaşı, kumtaşı seviyeleri, konglomera, volkanik cam, kumtaşı, karbonat çimentolu tüfit seviyeleri ve trakiandezitik tüf içeren Ömer-Gecek formasyonu gelmektedir. Üst Miyosen yaşı ı volkanik kayaçlar ve alüvyon ise bölgedeki en genç birimlerdir(Ulutürk 2009, Yıldız vd. 2012).

Sıcak su kaynak ve kaplıcaları yönünden oldukça, zengin olan bu bölgede; kalkşist, Paleozoyik yaşlı kuvarsit, kalkşistler ve kristalize kireçtaşı ile Neojen konglomera, kireçtaşı kaya birimleri, kumtaşı ve yöredeki bütün fay zonları rezervuar kaya niteliğindedir(Erişen 1996).

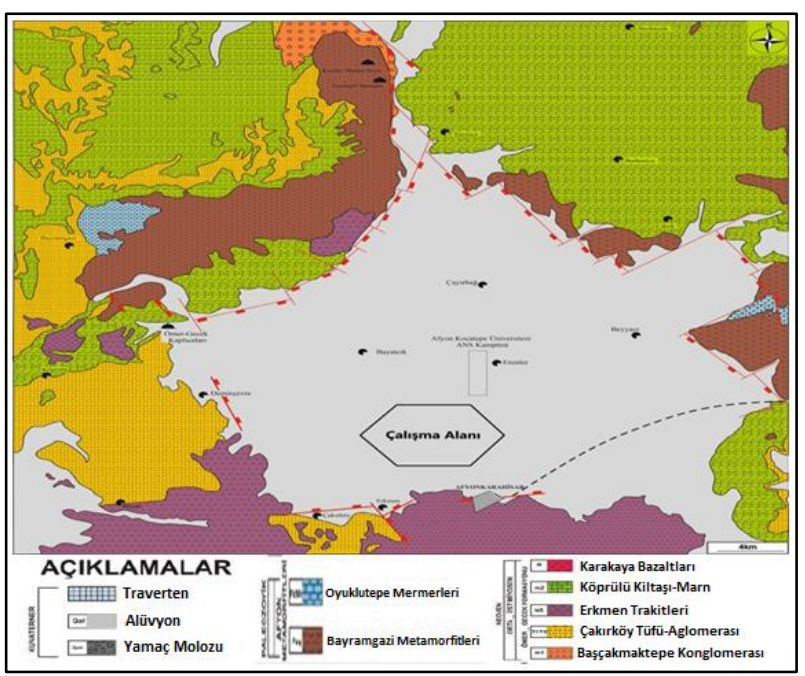

Şekil 2. Afyonkarahisar merkezi genel jeolojik haritası (Ulutürk 2009).

Afyonkarahisar ve çevresi, Ege Bölgesi sınırları içerisinde olup, iç Anadolu ve Ege Bölgesinin kesiştiği noktada bulunmaktadır. Afyonkarahisar ili, Tektonik olarak Ege Bölgesinin genişlemeli sismik etkisine maruz kaldığından dolayı farklı tarihlerde birçok deprem meydana gelmiştir(Yıldız 2012).

2011 yılında güncellenen Türkiye Diri Fay Haritasına göre inceleme bölgesini etkileyeceği düşünülen Simav ve Sultandağı Faylarından oluşan sistem içerisinde birçok aktif fay segmenti ve ilişkili genç havzalar yer almaktadır (Şekil 3).

ASFS, Batıda Sındırgı ile doğuda Ilgın arasında olup yaklaşık uzunluğu 400 km'dir. ASFS'nin kuzeybatı kısmı yedi sağ yanal doğrultu atımlı fay segmentinden oluşmaktadır.

Ortalama uzunluğu $30 \mathrm{~km}$ olan $A A G$ 'nin güneydoğu bölümü, KB-SE adıyla ve yaklaşık $130 \mathrm{~km}$ uzunluğunda aktif depresyon bölgesi olarak adlandırılmıştır (Koçyiğit 1984, Koçyiğit vd. 2000, Koçyiğit ve Özacar 2003, Emre vd. 2011, Özkaymak vd. 2017, Duman vd. 2018, Tiryakioğlu vd. 2018, KOERI 2019). 


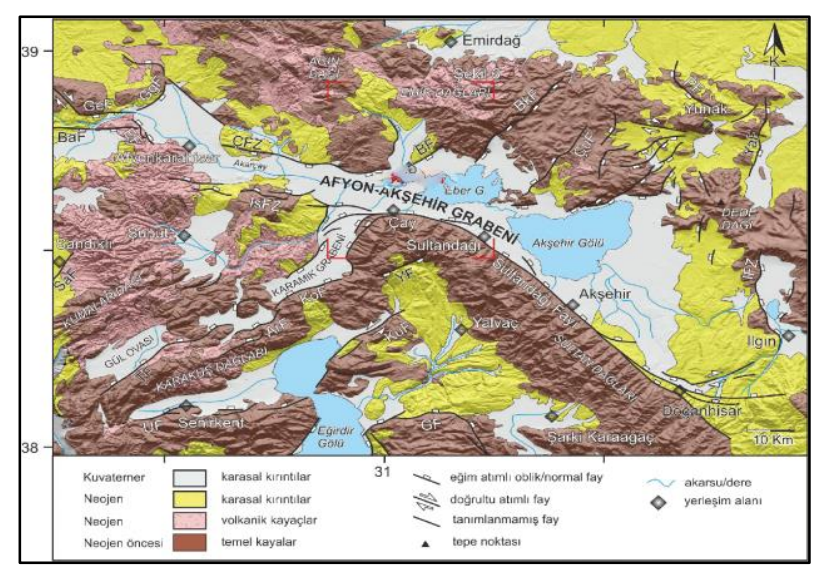

Şekil 3. Afyon-Akşehir Grabeni ve yakın çevresinin jeoloji haritası (Özkaymak vd. 2017).

Afyon-Akşehir Graben'in (AAG) orta kesiminde ve Bolvadin'in hemen güneyinde yer alan Maltepe ve Çay bölgelerinde yüzey kırılmalarının oluşmasına yol açan iki yıkıcı deprem, sırasıyla 3 Şubat 2002'de 6,3 ve 6,0 büyüklükleriyle meydana gelmiştir (Özden vd. 2002, Emre vd. 2003, Yürür vd. 2003, Akyüz vd. 2006, Tan vd. 2008). Ayrıca, AAG boyunca meydana gelen, büyüklükleri 2 ila 4 arasında olan yaklaşık 2000 deprem bu bölgedeki yüksek sismik aktiviteyi göstermektedir. Bunların çoğu 5,7 ile 6,3 arasında büyüklüklere sahip aktif normal faylarda meydana gelen depremlerle ilişkilidir. Afyonkarahisar sınırları içerisinde toplamda 31 adet aktif fay vardır. Bu fayların üretebileceği maksimum deprem büyüklükleri 6.18-6.86 arasında değişmektedir. Fayların uzunlukları ise $9-33 \mathrm{~km}$ arasında değişmektedir(Emre vd. 2018).

\subsubsection{Doğrusal Olmayan Analiz Yöntemi ile Sıvılaşma Riskinin Belirlenmesi}

Inceleme alanındaki yerel zemin tabakalarında meydana gelebilecek depremlerin özelliklerini belirleyebilmek amacıyla, bölgenin sismik tehlike verileriyle uyumlu doğrusal olmayan analiz yöntemi kullanılarak sıvılaşma analizleri yapılır. Sıvılaşma analizlerinde izlenen adımlar şöyle özetlenebilir:

a) Zemin özelliklerinin belirlenmesi: Jeolojik, geoteknik ve jeofizik yöntem esaslarına dayalı olarak araziden alınmış olan zemin numuneleri üzerinde fiziksel ve mekanik özelliklerin tayini ve bu deneylere bağlı olarak temsili zemin profilinin belirlenmesi gerekmektedir. Kayma modülünün(G) derinliğe bağlı olarak değişimini temsil eden; profilin kayma dalgası hız $\left(\mathrm{V}_{s}\right)$ ve kayma modülü ile birlikte sönüm oranı eğrilerinin şekil değiştirme genliği değişimleri de belirlenmelidir.

b) İvme-zaman deprem kayıtlarının seçimi: Inceleme bölgesi için sismik tehlike analizlerinde kullanılacak deprem verileri sismik tehlike çalışması ile öngörülen depremin büyüklüğü, depremin bölgeye uzaklığı ve faylanma sistemi ile uyumlu kayıtlar seçilmelidir (Ansal ve Tönük 2007). Aynı zamanda sismik tehlike çalışmasında, bölgesel olarak belirlenmiş en büyük ivme spektrumu ve ivme ile de uyumluluk mutlaka olmalıdır. Ön görülen depreme uyumluluk, daha önce kaydedilmiş depremlerin ivme büyüklükleri bölgeye uyumlu olacak şekilde sabit bir katsayı kullanarak ölçeklendirilmesi gerekmektedir. Genellikle tabaka hareketinin modellenmesi, sahada hipotetik olarak zemin profili tabanında yüzeylenmiş anakayanın varlığı kabul edilerek yapılmaktadır.

c) Sıvılaşma risk analizleri: Zemin profili özelliklerini temsil eden parametrelerin tanımlanmasındaki zorluklar ve belirsizlikler dikkate alınarak, analizler genellikle bu parametre değerlerinin ortalaması (en iyi tahmin) kullanılarak yapılır. Sıvılaşma analizinin yapılabilmesi için çalışma alanının zemin tipine göre aşırı boşluk suyu basıncı oluşum modelleri kullanılarak elde edilir.

d) Zemin sıvılaşma riskinin değerlendirilmesi: Yapılacak olan zemin araştırma çalışmaları, koni penetrasyon deneyinin (CPT) ve/veya standart penetrasyon deneyi (SPT)'nin yapımına ek olarak, inceleme yapılacak zemin tabakalarının su muhtevası, dane çapı dağılımı ve kıvam limit değerlerinin belirlenmesini kapsamaktadır. Potansiyel olarak sıvılaşma riski bulunan zeminler; yeraltı su seviyesinin altında yer alan kum, siltli killi kum, çakıllı kum, plastik olmayan silt-kum ve silt karışımları olarak tanımlanmaktadır.

Bir boyutlu zemin davranış analizleri; basit olmasının yanı sıra güvenli tarafta kalmamızı sağlayan sonuçlar vermesi sebebiyle yaygın olarak kullanılmaktadır. Bu tür analizler esas alınarak tasarlanmış olan birçok projenin depremlerde yeterli dayanımı gösterdiğini bilmekteyiz. Bir boyutlu dinamik analizler, efektif 
gerilmeye bağlı olarak modül azalımı ve sönüm eğrilerinin ilişkileri benimsenerek yapılmaktadır. Bu ilişkiler Darendeli(2001) tarafından geliştirilen dört parametre modeline bağlı olarak belirlenen her bir zemin profilinin alt tabakası için seçilen zeminin tipi dikkate alınarak üretilmiş ve geliştirilmiştir. Dinamik analizlerde, zemin profilinin tabaka kalınlıkları, tabakaların birim hacim ağırlığı, malzeme parametreleri, zemin sınıfı ve zeminin kayma dalgası hızı $\left(V_{s}\right)$ değerleri kullanılarak yapılmıştır.

Bu çalışmada, sahaya özgü deprem özellikleri, temsili zemin profilleri dikkate alınarak bir boyutlu doğrusal olmayan yöntemle DeepSoil v6.1 programı kullanılarak belirlenmiştir. Inceleme alanında 124 adet sondaj kuyusu ve bu sondajlardan elde edilen standart penetrasyon deneyi vuruş sayısına bağlı olarak kayma dalgası hızı değerleri İyisan (1996)'ya göre belirlenmiş ve sondaj kuyularının bir boyutlu analizleri yapılmıştır.

\subsection{Metod}

Inceleme alanında yapılan 124 adet sondajın ortalama derinliği $15-20 \mathrm{~m}$ arasında, yeraltı su seviyesi derinliği ise 3-6 m arasında değişmektedir. Sondaj kuyularında yapılan Standart Penetrasyon Testlerinde (SPT), ASTM D 1586-99 standardı esas alınmıştır.

$\mathrm{Bu}$ kapsamda standart penetrasyon deneyinden elde edilen numuneler üzerinde su muhtevası, Atterberg limitleri, elek analizi ve tek eksenli basınç deneyleri yapılmıştır. Laboratuvar test sonuçları değerlendirilmesi sonucu her bir tabakanın zemin sınıflandırması yapılarak derinliğe bağlı çalışma bölgesinin genel jeolojisi oluşturulmuştur.

Çalışma alanında zemin profilinin 0-7.50 metre arası düşük plastisiteli kil(CL) ve yüksek plastisiteli kil(CH) bulunurken 7.50-18.00 metre arası siltli kum (SM) ve killi kum (SC), 18.00-20.00 metre arasında da düşük plastisiteli kil(CL) ve yüksek plastisiteli kil(CH) formasyonlarından oluşmaktadır. Sondaj kuyularından alınan numunelerin su muhtevaları \% 6.58 ile \% 38.60 arasında, doğal birim ağırlıkları ise $15.27-19.93 \mathrm{kN} / \mathrm{m}^{3}$ arasında değişmektedir.
Çizelge 1. Çalışma alanındaki sondaj kuyularının derinliğe bağlı olarak genel SPT ve Kayma dalga hızı değerleri

\begin{tabular}{cccc}
\hline Derinlik $(\mathbf{m})$ & $\begin{array}{c}\text { Zemin } \\
\text { Sınıf }\end{array}$ & $\begin{array}{c}\text { SPT Değeri } \\
\left(\mathbf{N}_{\mathbf{3 0}}\right)\end{array}$ & $\begin{array}{c}\text { Kayma Dalga } \\
\text { Hızı }\left(\mathbf{V}_{\mathbf{s}}\right)\end{array}$ \\
\hline $1.50-1.95$ & $\mathrm{CH}-\mathrm{CL}$ & 14 & 201 \\
\hline $3.00-3.45$ & $\mathrm{CL}-\mathrm{CH}$ & 14 & 201 \\
\hline $4.50-4.95$ & $\mathrm{CL}-\mathrm{CH}$ & 14 & 201 \\
\hline $6.00-6.45$ & $\mathrm{CL}-\mathrm{CH}$ & 15 & 208 \\
\hline $7.50-7.95$ & $\mathrm{SM}$ & 17 & 222 \\
\hline $9.00-9.45$ & $\mathrm{SM}-\mathrm{SC}$ & 17 & 222 \\
\hline $10.50-10.95$ & $\mathrm{SM}-\mathrm{SC}$ & 20 & 242 \\
\hline $12.00-12.45$ & $\mathrm{SM}-\mathrm{SC}$ & 21 & 248 \\
\hline $13.50-13.95$ & $\mathrm{SM}$ & 22 & 254 \\
\hline $15.00-15.45$ & $\mathrm{SM}$ & 21 & 248 \\
\hline $16.50-16.95$ & $\mathrm{SM}$ & 22 & 254 \\
\hline $18.00-18.45$ & $\mathrm{CL}-\mathrm{CH}$ & 16 & 215 \\
\hline $19.50-19.95$ & $\mathrm{CL}-\mathrm{CH}$ & 13 & 193 \\
\hline
\end{tabular}

Kayma dalgası hızlarının 180-360 arasında olduğu bölgeler ZD yerel zemin sınıfını yani "Sert zemin" (Orta sıkı-sıkı kum, çakıl veya çok katı kil) tabakalarından oluştuğunu göstermektedir.

Çizelge 2. Yerel zemin sınıfları (TBDY 2018).

\begin{tabular}{ccc}
\hline Zemin Sınıfı & $\mathbf{V}_{\mathbf{s 3 0}}$ (m/sn) & Zemin Cinsi \\
\hline ZA & $>1500$ & Sert Kaya \\
\hline ZB & $760-1500$ & Kaya \\
\hline ZC & $360-760$ & $\begin{array}{c}\text { Sert zemin veya } \\
\text { yumuşak kaya }\end{array}$ \\
\hline ZD & $180-360$ & Sert zemin \\
\hline ZE & $<180$ & Yumuşak Zemin \\
\hline ZF & N/A & $\begin{array}{c}\text { Sahaya özel } \\
\text { değerlendirme gerekli }\end{array}$ \\
\hline
\end{tabular}

İnceleme bölgesi zeminleri için her sondaj noktasında SPT-N değerlerinden kayma dalgası hızını belirlemek amacıyla İyisan (1996) tarafından geliştirilen tüm zeminler için geçerli ampirik bağıntı tercih edilmiştir.

$V S=51.5 N^{0,516}$

$V_{s}:$ Kayma dalgası hızı $(\mathrm{m} / \mathrm{s})$

$\mathrm{N}$ : Ham SPT darbe sayısı 
Akşehir-Simav Fay Sistemi (ASFS) ve KD-GB yönlü faylar üzerinde meydana gelmiş olan bütün depremler Afyonkarahisar ve çevresinin sismik tehlike açısından oldukça aktif bir sistemin içinde olduğunu göstermektedir. Akşehir-Simav Fay Sistemi üstünde, bölgenin kuzeybatıda Çukurören ile güneydoğusunda Çobanlar ilçesi arasında kalmış olan yaklaşık olarak $113 \mathrm{~km}$ uzunluğa sahip hat boyunca normal/oblik/doğrultu atımlı fay sistemlerinden oluşmaktadır.

Anakaya mostrasındaki yer hareketi olarak bu faylanma türleri dikkate alınarak yönetmeliğe göre seçilmiş olan 11 farklı deprem kaydı Çizelge 3'de verilmiştir.

Çizelge 3. Dinamik analizlerde kullanılan deprem kayıtları(AFAD, PEER)

\begin{tabular}{|c|c|c|c|c|}
\hline Deprem Adı & İstasyon & $\begin{array}{c}\text { Derinlik } \\
(\mathbf{k m})\end{array}$ & $\begin{array}{l}\text { PGA } \\
\text { (g) }\end{array}$ & $\begin{array}{c}\text { Büyüklük } \\
(\mathrm{Mw})\end{array}$ \\
\hline $\begin{array}{c}\text { 19/08/1976 } \\
\text { Denizli }\end{array}$ & 2001 & 20 & 0.35 & 5.0 \\
\hline $\begin{array}{c}\text { 13/03/1992 } \\
\text { Erzincan }\end{array}$ & 2402 & 23 & 0.41 & 6.6 \\
\hline $\begin{array}{c}\text { 17/01/1995 } \\
\text { Kobe }\end{array}$ & Takarazuka & 17.6 & 0.82 & 6.9 \\
\hline $\begin{array}{c}\text { 01/10/1995 } \\
\text { Dinar }\end{array}$ & 0302 & 5 & 0.28 & 6.1 \\
\hline $\begin{array}{c}\text { 27/06/1998 } \\
\text { Ceyhan }\end{array}$ & 0105 & 23 & 0.22 & 6.2 \\
\hline $\begin{array}{c}\text { 17/08/1999 } \\
\text { Kocaeli }\end{array}$ & 4106 & 15.9 & 0.21 & 7.4 \\
\hline $\begin{array}{c}\text { 21/09/1999 Chi } \\
\text { Chi }\end{array}$ & TCU & 8 & 0.18 & 7.3 \\
\hline $\begin{array}{l}\text { 12/11/1999 } \\
\text { Düzce }\end{array}$ & 8101 & 11 & 0.41 & 7.2 \\
\hline $\begin{array}{c}\text { 01/05/2003 } \\
\text { Bingöl }\end{array}$ & 1201 & 6 & 0.55 & 6.1 \\
\hline $\begin{array}{c}23 / 10 / 2011 \\
\text { Van }\end{array}$ & 6503 & 19.02 & 0.18 & 6.7 \\
\hline $\begin{array}{c}\text { 20/03/2019 } \\
\text { Denizli }\end{array}$ & 2017 & 10.76 & 0.36 & 5.5 \\
\hline
\end{tabular}

Olası bir depremin mevcut yapı ve yapı stoğu üzerindeki etkilerinin belirlenmesinde deprem özelliklerinin ve zemin yüzeyindeki olası zemin davranışlarının dikkate alınması gerekmektedir. Bu amaçla zemin kesitindeki zemin tabakaları kapsamlı bir şekilde belirlenmiş ve incelenen bölgede sismik tehlike analizine uygun ivme zaman kayıtları seçilmiştir.
Türkiye Bina Deprem Yönetmeliği kapsamında aşağıda dört farklı deprem yer hareketi düzeyi tanımlanmıştır.

DD-1 Deprem Yer Hareketi; En büyük deprem yer hareketi olarak ifade edilmektedir. Spektral büyüklüklerin 50 yılda aşılma olasılığının \%2 ve bu duruma karşılık gelen tekrarlanma periyodunun 2475 yıl olduğu "Çok Seyrek" deprem yer hareketini ifade etmektedir.

DD-2 Deprem Yer Hareketi; Standart tasarım deprem yer hareketi olarak da ifade edilmektedir. Spektral büyüklüklerin 50 yılda aşılma olasılığının \%10 ve bu duruma karşılık gelen tekrarlanma periyodunun 475 yıl olduğu "Seyrek Deprem" yer hareketini ifade etmektedir.

DD-3 Deprem Yer Hareketi; Spektral büyüklüklerin 50 yılda aşılma olasıı̆ı̆ının \%50 ve bu duruma karşılık gelen tekrarlanma periyodunun 72 yıl olduğu "Sık Deprem" yer hareketini belirtmektedir.

DD-4 Deprem Yer Hareketi; Servis deprem yer hareketi olarak da ifade edilmektedir. Spektral büyüklüklerin 50 yılda aşılma olasılığının \%68 (30 yılda aşılma olasıı ığının \%50) ve bu duruma karşılık gelen tekrarlanma periyodunun 43 yıl olduğu "Çok Sık Deprem" yer hareketini ifade etmektedir.

Gerçek deprem kayıtlarının yönetmeliklerde belirlenen şartları sağlayacak şekilde seçilip tasarım ivme spektrumu ile uyuşacak şekilde ölçeklenmesi gerekir. Gerçek deprem kayıtlarının tasarım ivme spektrumuna uygun olacak şekilde ölçeklenmesi için pek çok yöntem mevcuttur. Bu yöntemler, zaman tanım alanındaki yöntemler ve frekans tanım alanındaki yöntemler olmak üzere ikiye ayrılır. Zaman tanım alanındaki ölçekleme yöntemlerinde kaydın frekans içeriği değiştirilmeksizin sadece kaydın genliği ile oynanır. Frekans tanım alanındaki ölçekleme yöntemlerinde ise tasarım ivme spektrumuna bir eşlik bulmak için yer hareketi kaydının frekans içeriği değiştirilir. Türkiye Deprem Şartnamesinde tanımlanan esaslara uygun olarak seçilen gerçek deprem kayıtları zaman ve frekans tanım alanında ölçekleme yöntemleri kullanılarak önerilen tasarım ivme spektrumlarıla eşleştirilmiştir. Sismik tehlike çalışmasında belirlenmiş en büyük ivme ve ivme spektrumu ile de 
uyumluluk aranmalıdır. Tasarım depremine uyumluluk, kaydedilmiş ivme büyüklüklerinin sabit bir katsayı kullanılarak ölçeklendirilmesi ile sağlanabilir. Genellikle yer hareketinin modellenmesi sahada farazi olarak yüzeylenmiş anakayanın varlığı kabul edilerek yapılır(Civelekler vd. 2018).

İnceleme alanı için özel olarak belirlenen deprem yer hareketleri de en büyük ivme kaydına göre analiz programında bire bir ölçeklendirilerek kullanılmış ve Çizelge 4'de verilmiştir.
Çizelge 4. Inceleme alanının deprem yer hareketi düzeyine göre ivme değerleri (https://deprem.afad.gov.tr)

\begin{tabular}{cc}
\hline Deprem Yer Hareketi Düzeyi & $\begin{array}{c}\text { Ivme Değerleri } \\
\text { (g) }\end{array}$ \\
\hline DD-1 (Tekrarlanma periyodu 2475 Yıl) & 0.64 \\
\hline DD-2 (Tekrarlanma periyodu 475 Yıl) & 0.33 \\
\hline DD-3 (Tekrarlanma periyodu 72 Yıl) & 0.12 \\
\hline DD-4 (Tekrarlanma periyodu 43 Yıl) & 0.08 \\
\hline
\end{tabular}

Yönetmelik uyarınca seçilen 11 farklı gerçek deprem kaydı, çalışma alanı için sistemden elde edilen maksimum ivme değerlerine göre DeepSoil analiz programında DD-1, DD-2, DD-3 ve DD-4 yer hareketi seviyesine göre bire bir ölçeklendirilerek her bir kuyunun tabanında tanımlanmıştır (Şekil 4).

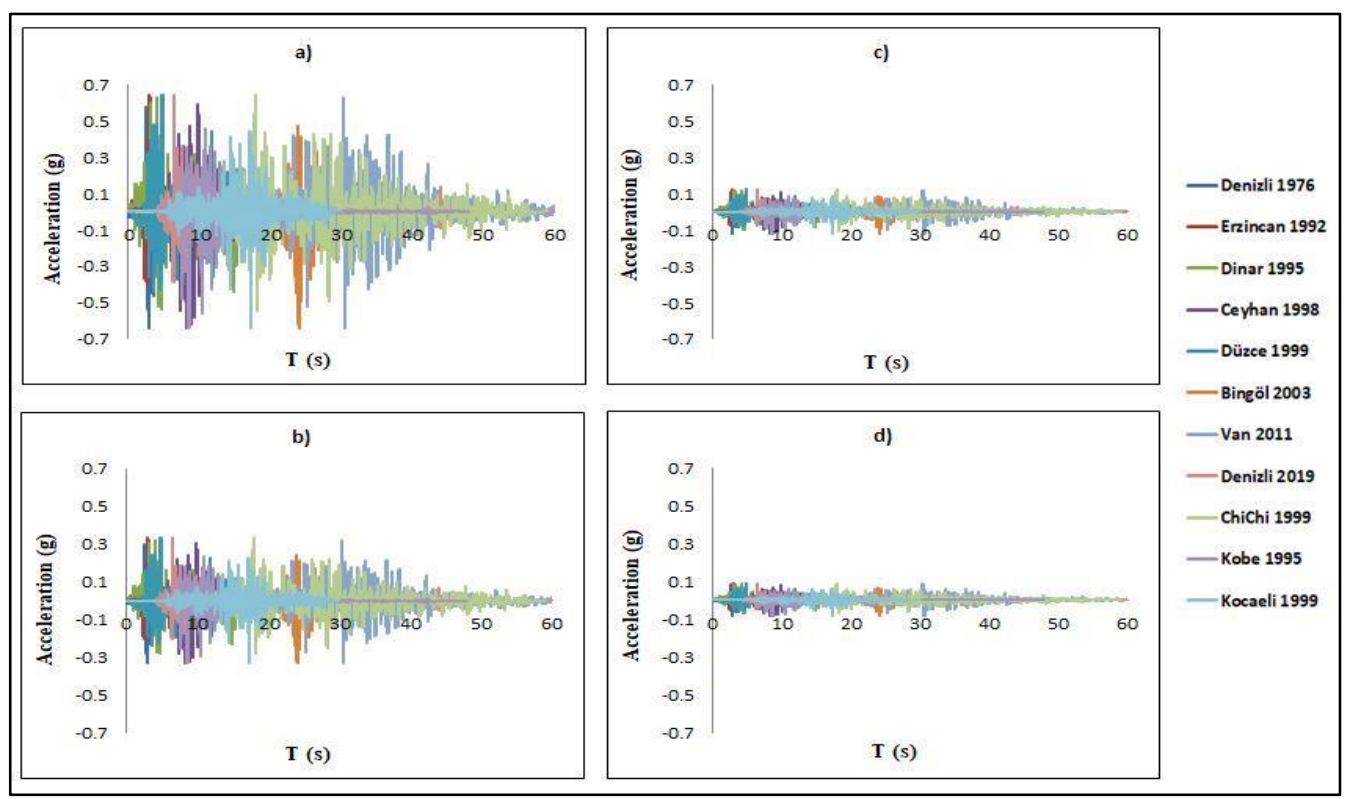

Şekil 4. Çalışma alanı ivmelerine göre ölçeklendirilmiş gerçek deprem kayıtları a)DD-1 deprem yer hareketi seviyesi, b)DD-2 deprem yer hareketi seviyesi, c)DD-3 deprem yer hareketi seviyesi, d)DD-4 deprem yer hareketi seviyesi.

\subsubsection{Sıvılaşma Analizi Örnek Uygulaması}

Bir zemin profilinde aşırı boşluk suyu basıncının meydana gelmesi ile birlikte zeminde sıvılaşma potansiyelinin artmasına yol açabilmektedir. DeepSoil programında sıvılaşma analizi, Doğrusal olmayan analiz yöntemiyle General Quadratic Model (GQ/H) formülasyonu kullanılmıştır.

Program kapsamında zemin çökelinde meydana gelen aşırı boşluk suyu basıncının yayılması ve tekrardan dağılması, zeminin iç ve dış tabakalarındaki suyun akış hızı ve belirli bir süre zarfındaki boşluk suyu basıncı oranına bağlı olarak analizler gerçekleştirilmektedir. Aşırı boşluk suyu basıncı oranı 1 değerine ulaştığında veya yaklaştığında, başka bir ifade ile efektif gerilmenin sıfır olması şartıyla, bu tip zemin tabakalarında sıvılaşma riski "vardır" veya "yüksek" olarak ifade edilmektedir. 
Bu çalışmada öncelikle, inceleme alanında yer alan geoteknik veriler kullanılarak, temsili zemin profilleri oluşturulmuştur. Temsili zemin profillerinin oluşturulması aşamasında, inceleme alanı için analizlerde Darendeli (2001) dinamik davranış modeli seçilmiştir.

Bunun yanı sıra, doğrusal olmayan dinamik analizlerde kullanılacak olan aşırı boşluk suyu basıncı oluşum modellerinden Dobry ve Matasovic (1993) ve Matasovic ve Vucetic (1995) seçilerek bu modellere ait parametreler hesaplanmıştır.

Oluşturulan temsili zemin profilleri ve hesaplanan aşırı boşluk suyu basıncı oluşum parametreleri DEEPSOIL programına aktarıldıktan sonra, analizlerde kullanılacak olan anakaya girdi hareketi seçilmiştir.

ZD yerel zemin sınıfına sahip çalışma bölgesinin zemin davranış analizleri için bir boyutlu olarak; yönetmeliğe göre sıvılaşma potansiyeli olan zeminlerde eşdeğer doğrusal analiz modeli ile frekans tanım alanında hesap yapılmayacağı için sıvılaşma analizleri zaman tanım alanında doğrusal olmayan analiz yöntemi kullanılarak yapılmıştır.

Bu çalışmada anakaya girdi hareketi olarak Çizelge 3'deki deprem kayıtları, Çizelge 4'deki ivme değerlerine göre ölçeklendirilerek 11 adet ivme kaydı kullanılmıştır.

Çalışmada kullanılan tüm sondaj profillerinin zemin mühendislik özellikleri ve parametreleri analiz programına girilerek doğrusal olmayan analiz yöntemi ile boşluk suyu basıncına bağlı olarak sıvılaşma analizi yapılmıştır.

Sıvılaşma analizi için, örnek olarak SK-62 zemin profilinin analizi yapılmış ve analizlere bağlı olarak program aşağıda gösterilen örnek sonucu vermiştir (Şekil 5).

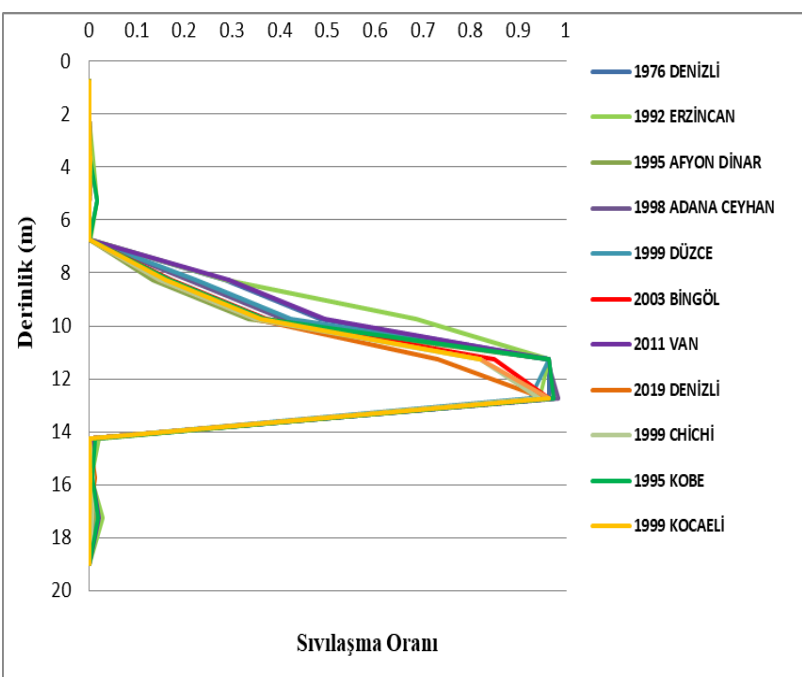

Şekil 5. Deprem yer hareketi DD-2'ye göre örnek sondaj kuyusunun sıvılaşma oranı değerlerinin derinlikle değişimi.

Yukarıda 11 deprem kaydı için verilen sıvılaşma oranı değerlerinin ortalaması alınarak derinlikle değişimi Şekil 5'de sunulmuştur. Şekil 6'ya baktığımızda örnek SK-62 zemin profiline uygulanan ivmenin, zemin profili boyunca sıvılaşma riskini göstermektedir.

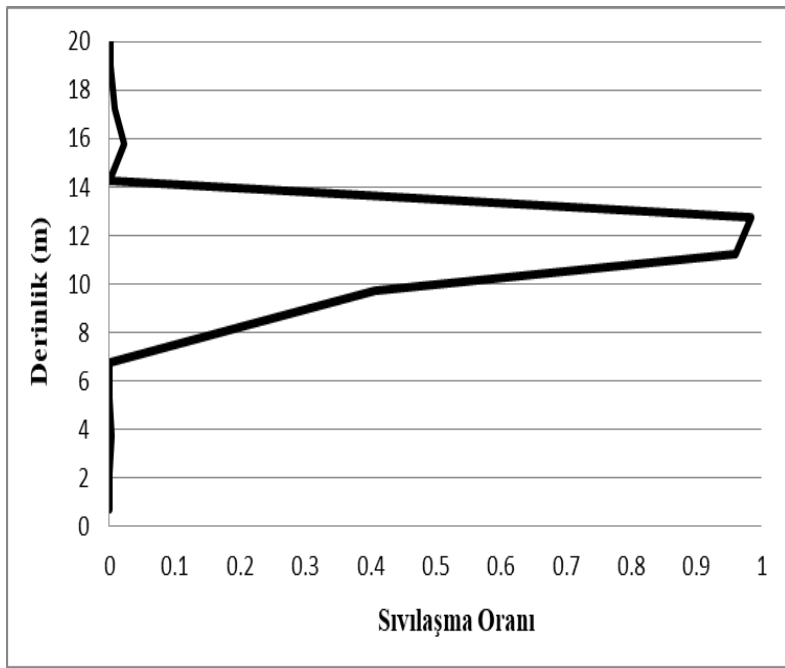

Şekil 6. Deprem yer hareketi DD-2'ye göre örnek sondaj kuyusunun ortalama sıvılaşma oranı değerlerinin derinlikle değişimi. 
Çalışma alanının genel zemin profili de dikkate alındığında $20 \mathrm{~m}$ derinlikten itibaren kil zeminde sıvılaşma oranı 0 iken, kumlu zemine doğru (8.00$14.00 \mathrm{~m}$ arası) yukarı doğru hareketi esnasında sıvılaşma riski oranı artmış ve (11.00-13.00 $\mathrm{m}$ arası) bu oran maksimum \%96 olarak tespit edilmiştir.

Genel zemin profiline göre 10.00 m'den itibaren ana kaya deprem ivmesinin tekrar kil zemin tabakasına girmesi sonucunda sıvılaşma riski oranında ani bir azalış görülerek \%1 sıvılaşma oranına düştüğü görülmektedir.

\section{Bulgular}

Bir boyutlu DeepSoil analiz programında, yönetmeliğin ön gördüğü şekilde zaman alanında doğrusal olmayan analiz yöntemi kullanılmıştır. Sıvılaşma analizinin yapılabilmesi için çalışma alanının zemin tipine göre aşırı boşluk suyu basıncı oluşum modelleri kullanılarak elde edilen sıvılaşma analizi haritaları Şekil 7, Şekil 8, Şekil 9 ve Şekil 10' da verilmiştir. Deprem yer hareketlerine göre DD-1, DD-2, DD-3 ve DD-4 şeklinde ayrı ayrı analizleri yapılmıştır.

Aşırı boşluk suyu basıncı oranı 1 değerine ulaştığında veya yaklaştığında, başka bir ifade ile efektif gerilmenin sıfır olması şartıyla, bu tip zemin tabakalarında sıvılaşma riski "vardır" veya "yüksek" olarak ifade edilmektedir. Çalışma alanı için analizleri yapılan bölgelerde elde edilen sıvılaşma değer aralıkları da Çizelge 5, 6, 7 ve 8'de verilmiştir.

\subsection{Deprem Yer Hareketi DD-1'e Göre SIvılaşma Analiz Sonuçları}

DD-1 doğrusal olmayan sıvılaşma analiz sonuçlarına göre elde edilen Şekil 7 incelendiğinde en küçük sıvılaşma riski 0.48 ile Battal Gazi mahallesinde görülürken, Erkmen, Hasan Karaağaç, Yeşilyurt, Orhan Gazi ve Dörtyol mahallelerinde ise 1.00 değerine yaklaştığı için sıvılaşma riski en yüksek bölgeler olarak belirlenmiştir.

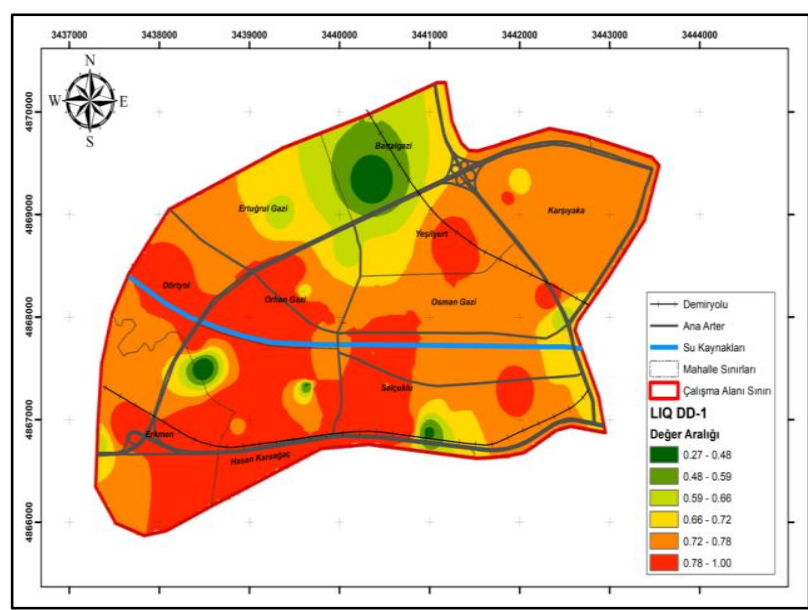

Şekil 7. Deprem yer hareketi DD-1'e göre sıvılaşma analiz haritası.

Zemin özellikleri ve depremin etkisiyle birlikte çalışma alanının belirlenen değer aralı̆̆ında sıvılaşma riskine maruz kalması beklenmektedir (Çizelge 5).

Çizelge 5. Deprem yer hareketi DD-1'e göre mahallelerin sıvılaşma analiz sonucu.

\begin{tabular}{cc}
\hline Mahalle Adı & Sıvılaşma Oranı \\
\hline Erkmen & $0.78-1.00$ \\
\hline Hasan Karaağaç & $0.78-1.00$ \\
\hline Selçuklu & $0.72-0.78$ \\
\hline Osman Gazi & $0.72-0.78$ \\
\hline Karşıyaka & $0.72-0.78$ \\
\hline Yeşilyurt & $0.78-1.00$ \\
\hline Battal Gazi & $0.48-0.59$ \\
\hline Ertuğrul Gazi & $0.56-0.72$ \\
\hline Orhan Gazi & $0.78-1.00$ \\
\hline Dörtyol & $0.78-1.00$
\end{tabular}

\subsection{Deprem Yer Hareketi DD-2'ye Göre Sıvılaşma Analiz Sonuçları}

DD-2 doğrusal olmayan sıvılaşma analiz sonuçlarına göre elde edilen Şekil 8 incelendiğinde en küçük sıvılaşma riski 0.30 ile Battal Gazi mahallesinde görülürken, Erkmen, Hasan Karaağaç, Orhan Gazi ve Dörtyol mahallelerinde ise 1.00 değerine yaklaştığı için sıvılaşma riski en yüksek bölgeler olarak belirlenmiştir. 


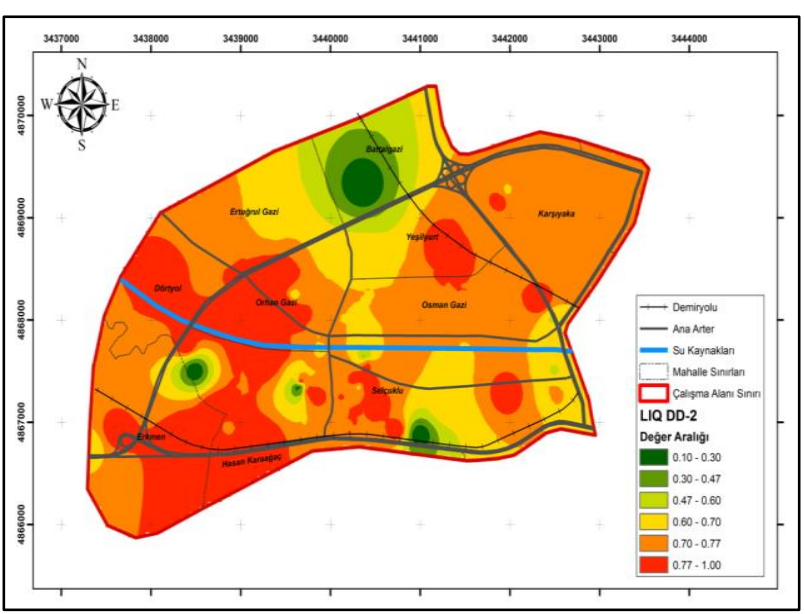

Şekil 8. Deprem yer hareketi DD-2'ye göre sıvılaşma analiz haritası.

Zemin özellikleri ve depremin etkisiyle birlikte çalışma alanının belirlenen değer aralığında sıvılaşma riskine maruz kalması beklenmektedir (Çizelge 6).

Çizelge 6. Deprem yer hareketi DD-2'ye göre mahallelerin sıvılaşma analiz sonucu.

\begin{tabular}{cc}
\hline Mahalle Adı & Sıvılaşma Oranı \\
\hline Erkmen & $0.77-1.00$ \\
\hline Hasan Karaağaç & $0.77-1.00$ \\
\hline Selçuklu & $0.60-0.70$ \\
\hline Osman Gazi & $0.70-0.77$ \\
\hline Karşıyaka & $0.70-0.77$ \\
\hline Yeşilyurt & $0.70-0.77$ \\
\hline Battal Gazi & $0.30-0.47$ \\
\hline Ertuğrul Gazi & $0.70-0.77$ \\
\hline Orhan Gazi & $0.77-1.00$ \\
\hline Dörtyol & $0.77-1.00$
\end{tabular}

\subsection{Deprem Yer Hareketi DD-3'e Göre SIvılaşma Analiz Sonuçları}

DD-3 doğrusal olmayan sıvılaşma analiz sonuçlarına göre elde edilen Şekil 9 incelendiğinde en küçük sıvılaşma riski 0.00 değeri ile Battal Gazi, Ertuğrul Gazi ve Orhan Gazi mahallesinde görülürken, Hasan Karaağaç mahallesinde ise 0.56 değeri belirlenmiştir. Yüzde olarak bu bölgenin \%56 sıvılaşma riski vardır diyebiliriz.

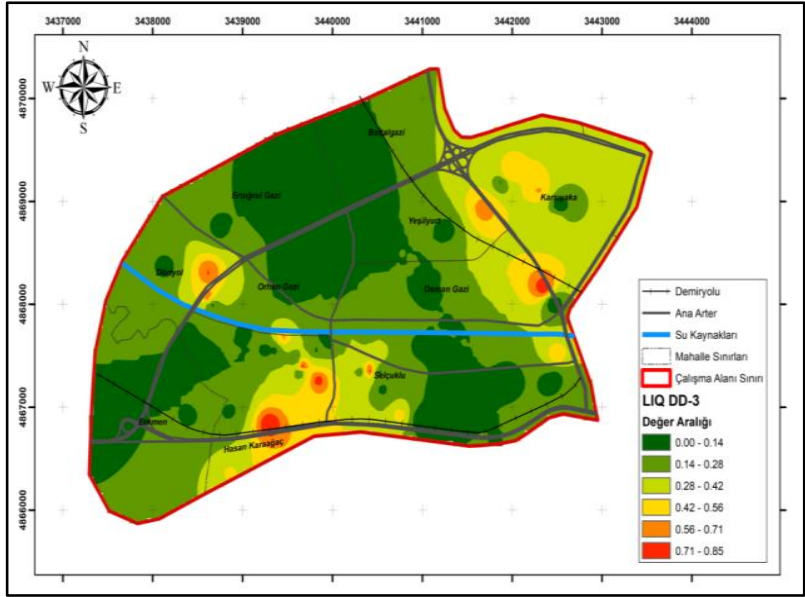

Şekil 9. Deprem yer hareketi DD-3'e göre sıvılaşma analiz haritası.

Zemin özellikleri ve depremin etkisiyle birlikte çalışma alanının belirlenen değer aralığında sıvılaşma riskine maruz kalması beklenmektedir (Çizelge 7).

Çizelge 7. Deprem yer hareketi DD-3'e göre mahallelerin sıvılaşma analiz sonucu.

\begin{tabular}{cc}
\hline Mahalle Adı & Sıvılaşma Oranı \\
\hline Erkmen & $0.14-0.28$ \\
\hline Hasan Karaağaç & $0.42-0.56$ \\
\hline Selçuklu & $0.14-0.28$ \\
\hline Osman Gazi & $0.14-0.28$ \\
\hline Karşıyaka & $0.28-0.42$ \\
\hline Yeşilyurt & $0.14-0.28$ \\
\hline Battal Gazi & $0.00-0.14$ \\
\hline Ertuğrul Gazi & $0.00-0.14$ \\
\hline Orhan Gazi & $0.00-0.14$ \\
\hline Dörtyol & $0.14-0.28$ \\
\hline
\end{tabular}

\subsection{Deprem Yer Hareketi DD-4'e Göre Sıvılaşma Analiz Sonuçları}

DD-4 doğrusal olmayan sıvılaşma analiz sonuçlarına göre elde edilen Şekil 10 incelendiğinde en küçük sıvılaşma riski 0.00 ile Erkmen, Selçuklu, Yeşilyurt, Battal Gazi, Ertuğrul Gazi, Orhan Gazi ve Dörtyol mahallelerinde görülürken, Hasan Karaağaç, Osman Gazi ve Karşıyaka mahallelerinde ise 0.28 değeri belirlenmiştir. Yüzde olarak oran verecek olursak bu üç bölgenin \%28 sıvılaşma riski vardır diyebiliriz. 


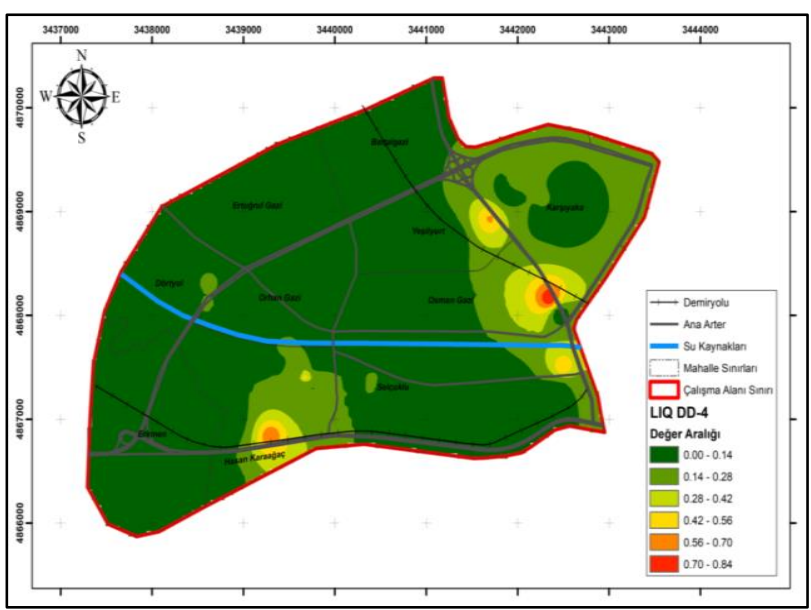

Şekil 10. Deprem yer hareketi DD-4'e göre sıvılaşma analiz haritası.

Zemin özellikleri ve depremin etkisiyle birlikte çalışma alanının belirlenen değer aralığında sıvılaşma riskine maruz kalması beklenmektedir (Çizelge 8).

Çizelge 8. Deprem yer hareketi DD-4'e göre mahallelerin sıvılaşma analiz sonucu.

\begin{tabular}{cc}
\hline Mahalle Adı & Sıvılaşma Oranı \\
\hline Erkmen & $0.00-0.14$ \\
\hline Hasan Karaağaç & $0.14-0.28$ \\
\hline Selçuklu & $0.00-0.14$ \\
\hline Osman Gazi & $0.14-0.28$ \\
\hline Karşıyaka & $0.14-0.28$ \\
\hline Yeşilyurt & $0.00-0.14$ \\
\hline Battal Gazi & $0.00-0.14$ \\
\hline Ertuğrul Gazi & $0.00-0.14$ \\
\hline Orhan Gazi & $0.00-0.14$ \\
\hline Dörtyol & $0.00-0.14$
\end{tabular}

Inceleme alanında kum, silt ve kil gibi zeminleri bünyesinde içeren tabakaların, meydana gelebilecek deprem anında sıvılaşma riskini belirleyebilmek amacıyla arazi deneyleri ve laboratuvar çalışmalarından elde edilen zemin parametreleri ile ve sismik verilerin birlikte kullanıldığı birçok kriter, deneysel formüller, ampirik bağıntılar ve analiz programları dikkate alınmıştır. Bütün bu kriterlerin yanı sıra inceleme alanında yeraltı su seviyesinin yüksek olması, zemin yapısının alüvyon olması ve aktif fayların bulunması sıvılaşma riski dikkate alınarak bir boyutlu dinamik analiz programı kullanılarak sıvılaşma risk analizi yapılmıştır.

Zemin tabakasının sıvılaşması, yeraltı su seviyesinin altında yer alan ve yüzeyden 20 m derinliğe kadar düşük kohezyonlu ya da kohezyonsuz zeminlerin deprem etkisi altında boşluk suyu basıncı artışına paralel kayma mukavemeti ve rijitliğinde ciddi oranda azalış olduğu gözlenmektedir. Deprem yer hareket düzeylerinin hepsi için sıvılaşma analizleri yapılmış fakat yapı tasarımlarında DD-1 ve DD-2 deprem yer hareketi düzeyi dikkate alınmaktadır.

Analiz sonuçlarına göre de inceleme bölgesinin genelinde DD-1 ve DD-2 deprem yer hareketlerine göre yüksek sıvılaşma riskinin olduğu anlaşılmıştır. Inceleme alanının, aktif fayların meydana getirebileceği deprem etkisi altında bulunduğu göz önüne alınırsa sıvılaşmaya bağıı oturmaların olması kaçınılmaz bir gerçektir. Bu tip oturmaların yapılara ciddi hasarlar verebilecek düzeyde olması sebebiyle, tasarlanan yapının temel zemininde iyileştirme yapılması gerekmektedir. Deprem sarsıntısı esnasında yanal zemin direncinin de ciddi oranda azalacağı dikkate alınmalıdır.

\section{Tartışma ve Sonuç}

- Deprem yer hareketi düzeyi (DD-1) doğrusal olmayan sıvılaşma analiz sonuçlarına göre en düşük sıvılaşma riski 0.48 ile Battal Gazi mahallesinde görülürken, Erkmen, Hasan Karaağaç, Yeşilyurt, Orhan Gazi ve Dörtyol mahallelerinde ise 1.00 değerine yaklaştığı için sıvılaşma riski en yüksek bölgeler olarak tespit edilmiştir.

- Deprem yer hareketi düzeyi (DD-2) doğrusal olmayan sıvılaşma analiz sonuçlarına göre en düşük sıvılaşma riski 0.30 ile Battal Gazi mahallesinde görülürken, Erkmen, Hasan Karaağaç, Orhan Gazi ve Dörtyol mahallelerinde ise 1.00 değerine yaklaştığı için sıvılaşma riski en yüksek bölgeler olarak tespit edilmiştir. 
- Deprem yer hareketi düzeyi (DD-3) doğrusal olmayan sıvılaşma analiz sonuçlarına göre en düşük sıvılaşma riski 0.00 değeri ile Battal Gazi, Ertuğrul Gazi ve Orhan Gazi mahallesinde görülürken, Hasan Karaağaç mahallesinde ise 0.56 olarak tespit edilmiştir.

- Deprem yer hareketi düzeyi (DD-4) doğrusal olmayan sıvılaşma analiz sonuçlarına göre en düşük sıvılaşma riski 0.00 ile Erkmen, Selçuklu, Yeşilyurt, Battal Gazi, Ertuğrul Gazi, Orhan Gazi ve Dörtyol mahallelerinde görülürken, Hasan Karaağaç, Osman Gazi ve Karşıyaka mahallelerinde ise 0.28 olarak tespit edilmiştir.

- Sıvılaşma analizi sonuçlarına göre inceleme alanı için önerilen zemin iyileştirme metodlarından Jet Grout, Deep Mixing vb. yöntemler kullanılarak granüler zeminlerin başlangıçtaki boşluk oranları ve sıkışabilirliklerin azaltılması bunun yanı sıra içsel sürtünme açıları, taşıma gücü ve sıvılaşmaya karşı olan dirençlerin de artırılması ile meydana gelebilecek olumsuzlukların önüne geçilebileceği düşünülmektedir.

- Inceleme alanının alüvyon yapısı ve yeraltı su seviyesinin yüksek olması, deprem etkisiyle birlikte yer hareketlerini önemli ölçüde etkileyebileceği gözlenmiştir. Bu nedenle önemli yapılar için sahaya özel bir tasarım yaklaşımının benimsenmesi gerekmektedir.

- Elde edilen mikrobölgeleme haritaları, mevcut yapıların depreme dayanıklılığının değerlendirilmesinde ve yeni inşa edilmesi planlanan yapıların tasarımında faydalı olacağı düşünülmektedir. Daha güvenli yapılaşma için aynı alanda yapılan zemin etüt sonuçlarından elde edilen zemin profilinin de göz ardı edilemeyeceği açıkça görülmektedir.
- Inceleme alanında yeraltı su seviyesinin yüksek olması, zemin profili ve deprem etkisinden dolayı sıvılaşma riskini artırmaktadır. Önemli parametrelerden birisi olan yeraltı su seviyesinin drenaj yapılarıyla düşürülmesi ve sonrasında derin sıkıştırma yöntemleri ile iyileştirme yapılmasının etkili olabileceği düşünülmektedir.

- Önerilen metotların uygulamada ekonomik ve güvenli sonuçların elde edilmesinde yararlı olacağı beklenmektedir. Bu metotların sıvılaşma potansiyeli olan zemin profillerinde zemin sıvılaşma potansiyelini azaltıcı ve sıvılaşmayı önleyici yöntemler olarak kullanılabileceği görülmüştür.

\section{Kaynaklar}

Akyüz, S., Uçarkuş, G., Şatır, D., Dikbaş, A., Kozacı, Ö., 2006. 3 Şubat 2002 Çay Depreminde Meydana Gelen Yüzey Kırı̆ı̆ı Üzerinde Palaeosismolojik Araştırmalar, Yerbilimleri, 27, 41-52.

Ansal, A. ve Tönük, G., 2007. Source and Site Effects for Microzonation, Theme Lecture. 4th International Conference on Earthquake Geotechnical Engineering, 4, 73-92.

Bayrakçı, E., Pekkan, E., Avdan, U., Güney, Y., 2013. Coğrafi Bilgi Sistemleri Kullanılarak Sondaj Derinliğinin Sivılaşma Analizine Etkisinin Belirlenmesi (Eskişehir Örneği), Harita Teknolojileri Elektronik Dergisi, 2, 5060.

Bray, J., Cubrinovski, M., Zupan, J. and Taylor, M., 2014. Liquefaction Effects on Buildings In The Central Business District of Christchurch, Earthquake Spectra, 30, 85-109.

Civelekler, E., Okur, D. V., Afacan, K. B., 2018. Eşdeğer Analiz Yöntemi ile Belirlenen Zeminin Büyütme Değerlerinin Coğrafi Bilgi Sistemleri Kullanılarak Haritalanması: Eskişehir Örneği, VII. Uzaktan Algılama CBS Sempozyumu, Eskişehir, 1-10.

Darendeli, M. B., 2001. Development of A New Family of Normalized Modulus Reduction and Material 
Damping Curves. Architectural and Environmental Engineering, The University of Texas, Austin, Texas.

Değerliyurt, M., 2014. Settlement Suitability Analysis of Local Ground Characteristics In Iskenderun: A Case Study. Procedia-Social and Behavioral Sciences, 120, 637-644.

Duman, T. Y., Çan, T., Emre, Ö., Kadirioğlu, F. T., Başarır, Baştürk, N., 2018. Seismotectonic Database of Turkey. Bulletin of Earthquake Engineering, 16, 3277-3316.

Emre, Ö., Duman, T. Y., Doğan, A., Özalp, S., Tokay, F., 2003. Surface Faulting Associated with The Sultandağı Earthquake (Mw 6.5) of 3 February 2002, Southwestern Turkey. Seismological Research Letters, 74, 382-392.

Emre, Ö., Duman, T. Y., Özalp, S., Şaroğlu, F., Olgun, Ş., 2018. Active Fault Database of Turkey. Bulletin of Earthquake Engineering, 16, 3229-3275.

Emre, Ö., Duman, T.Y., Özalp, S., Olgun, Ş., and Elmacı, H., 2011. Active Fault Map of Turkey (Scale 1:250000), Afyon (NJ 36-5) Quadrangle. General Directorate of Mineral Research and Exploration Special Publication Series, 7, 1.

Erişen, B., 1996. Afyon Bölgesi Ömer-Gecek Jeotermal Alanında Yapılan AF-1 ve AF-3 Sondajlarına İlişkin Kuyu Bitirme Raporu, MTA Dergisi Rapor, Ankara, No:5623, 96.

İyisan, R., 1996. Relationship Between Shear Wave Velocity and Penetration Test Results in Soils. Technical Journal of Turkish Chamber of Civil Engineers, 7, 371-374.

Koçyiğit, A., 1984. Güneybatı Türkiye ve Yakın Dolayında Levha İçi Yeni Tektonik Gelişim, Türkiye Jeoloji Kurumu Bülteni, 27, 1-15.

Koçyigit, A., Özacar, A., 2003. Extensional Neotectonic Regime Through The NE Edge of Outer Isparta Angle, SW Turkey: New Field and Seismic Data. Turkish Journal of Earth Sciences, 12, 67-90.

Koçyiğit, A., Unay, E., Saraç, G., 2000. Epipodic Graben Formation and Extensional Neotectonic Regime In West Centaral Anatolia and Isparta Angle: A Case Study In The Akşehir Afyon Graben, Turkey. Journal Geological Society of London, 173, 405-421.
Kramer, S.L., 1996. Geotechnical Earthquake Engineering. Prentice Hall, Upper Saddle River, New Jersey, 254-303.

Matasovic, N., Dobry, R., 1993. Seismic Response of Composite Horizontally-layered Soil Deposits, Ph.D. Thesis, University of California, Los Angeles, 450-452.

Matasovic, N., Vucetic, M., 1995. Generalized Cyclic Degradation-Pore Pressure Generation Model for Clays. ASCE Journal of Geotechnical and Geoenvironmental Engineering, 121, 1, 33-42.

Özden, S., Kavak, K. Ş., Koçbulut, F., Över, S., Temiz, H., 2002. 2002.02.03 Çay (Afyon) Earthquakes. Geological Bulletin of Turkey, 45, 49-56.

Özkan M.Y., 2017. Zemin Dinamiğine Giriş, Nobel Yayın Dağıtım, Ankara, 315-316.

Özkaymak, Ç., Sözbilir, H., Tiryakioğlu, İ., Baybura, T., 2017. Geologic, Geomorphologic and Geodetic Analyses of Surface Deformations Observed in Bolvadin (Afyon-Akşehir Graben, Afyon). Geological Bulletin of Turkey, 60, 169-188.

Pacific Earthquake Engineering Research Center (PEER), 2020

Saita, J., Nakamura, Y. and Sato, T., 2012. Liquefaction Caused by the 2011 off the Pacific Coast of Tohoku Earthquake and the Result of the Prior Microtremor Measurement. 15th World Conference on Earthquake Engineering, Portugal.

Tan, O., Tapırdamaz, M.C., Yörük, A., 2008. The Earthquakes Catalogues for Turkey. Turkish Journal of Earth Sciences, 17, 405-418.

Taşdelen, S., Çelik, S.B., Akyol, E., 2016. Irgıllı Beldes (Denizli) Yerleşim Alanının Jeolojik ve Jeoteknik Özellikleri, Pamukkale Üniversitesi Mühendislik Bilimleri Dergisi, 22, 213-219.

Tiryakioğlu, İ., Özkaymak, Ç., Baybura, T., Sözbilir, H., Uysal, M., 2018. Comparison of Palaeostress Analysis, Geodetic Strain Rates and Seismic Data in The Western Part of The Sultandağı Fault In Turkey. Annals of Geophysics, 61, 333-335.

Toprak, S. and Jinguuji, M., 2006. A New Test for Liquefaction Prediction: Electrical Resistivity Vibration 
Penetration Test, Eighth U.S. National Conference on Earthquake Engineering, April 18-22, San Francisco, California.

Toprak, S., Jinguuji, M., Manav, Y. and Manav, R., 2016. Soil Liquefaction At Hinode Area During 2011 Great East Japan Earthquakes, 4th International Conference on New Developments In Soil Mechanics and Geotechnical Engineering, TRNC,535-541, June 2-4, Near East University, Nicosia.

Tunçel, A., Özdağ, Ö.C., Pamuk, E., Akgün, M., 2019. Calculation of the soil dynamic amplification factor values by using microtremor data: A case study in Izmir (North). Journal of the Faculty of Engineering and Architecture of Gazi University, 34, 43-52.

Türkiye Bina Deprem Yönetmeliği (TBDY), 2018. Türkiye Cumhuriyeti İçişleri Bakanlığı Afet ve Acil Durum Yönetimi Başkanlığı, T.C. Cumhurbaşkanlığı Resmi Gazetesi, Tarih: 18 Mart 2018.

Ulutürk, Y., 2009. Ömer-Gecek (Afyonkarahisar) Dolayının Jeolojisi ve Suların Kökensel Yorumu, Doktora Tezi, Fen Bilimleri Enstitüsü, Süleyman Demirel Üniversitesi, Isparta, 179.

Yamaguchi, A., Mori, T., Kazama, M. and Yoshida, N., 2012. Liquefaction in Tohoku District During The 2011 Off The Pacific Coast of Tohoku Earthquake, Soils Foundation, 52, 811-829.

Yasuda, S., Harada, K., Ishikawa, K. and Kanemaru, Y., 2012. Characteristics of Liquefaction in Tokyo Bay Area by The 2011 Great East Japan Earthquake, Soils Foundation, 52, 793-810.

Yıldız, A., Dumlupınar, İ., Bağcı, M., Ulutürk, Y., Başaran, C., Erdoğan, E., 2012. Afyonkarahisar ve Çevresinin Depremselliği. Afyon Kocatepe Üniversitesi Fen Bilimleri Dergisi, 12, 2, 1-7.

Yürür, T., Köse, O., Demirbağ, H., Özkaymak, Ç., Selçuk, L., 2003. Could the Coseismic Fractures of a Lake Ice Reflect The Earthquake Mechanism? (Afyon Earthquakes of 2 February 2002, Central Anatolia, Turkey), Geodinamica Acta, 16, 83-87.

\section{internet kaynakları}

1-http://www.afad.gov.tr, (15.07.2020)

2-http://www.koeri.boun.edu.tr, (29.09.2020)

3-https://ngawest2.berkeley.edu, (30.10.2020) 